\title{
Evaluasi Kinerja Penyuluhan Pertanian Kecamatan Balongpanggang Kabupaten Gresik
}

\section{Evaluation of Performance of Agricultural Extension Services in Balongpanggang District Gresik Regency}

\author{
Resya Nurdyawati ${ }^{1 *}$, Teguh Soedarto ${ }^{2)}$, Sumartono $^{3)}$ \\ ${ }^{1}$ Mahasiswa Program Studi Magister Agribisnis, Fakultas Pertanian Universitas Pembangunan \\ Naional "Veteran" Jawa Timur \\ ${ }^{2,3}$ Dosen Program Studi Magister Agribisnis, Fakultas Pertanian Universitas Pembangunan \\ Naional "Veteran" Jawa Timur \\ Jl. Rungkut Madya, Surabaya, 60294, Jawa Timur, Indonesia
}

\begin{abstract}
Abstrak
Penyuluh pertanian sangat penting untuk mendorong dan menggerakkan petani dalam melakukan usahataninya agar lebih efisien dan efektif serta membangun dan menghasilkan sumber daya manusia (SDM) yang berkualitas. Pentingnya peranan penyuluh menyebabkan penyuluh pertanian mendapatkan perhatian lebih seperti adanya Peraturan Menteri Pertanian Nomor 91/Permentan/OT.140/9/2013 tentang Pedoman Evaluasi Kinerja Penyuluh. Kinerja penyuluh pertanian terkait erat dengan peran penyuluh pertanian dalam mengimplementasikan programprogram penyuluhan yang dapat merubah perilaku petani kearah yang lebih baik. Penelitian ini bertujuan untuk mengkaji tingkat kinerja penyuluh Balai Penyuluhan Pertanian (BPP) Balongpanggang. Pengambilan sampel dilakukan dengan menggunakan metode sensus sebanyak 7 penyuluh. Metode pengukuran menggunakan Standar Nilai Prestasi Kerja (NPK) untuk mengetahui kinerja penyuluh. Hasil penelitian menunjukkan kinerja penyuluh pertanian BPP Balongpanggang berada pada kategori cukup. Belum optimalnya kinerja penyuluh tersebut dikarenakan rendahnya pelaksanaan penyuluhan dalam bentuk demontrasi, temu-temu dan metode dalam bentuk kursus serta rendahnya penumbuhan dan pengembangan kelembagaan ekonomi petani dalam aspek jumlah dan kualitas.

Kata kunci : Evaluasi, Kinerja, Penyuluh
\end{abstract}

\section{Pendahuluan}

Upaya pembangunan pertanian tidak terlepas dari upaya pengembangan sumber daya manusia terutama petani sebagai pelaku utama kegiatan pertanian. Kecenderungan penurunan aktivitas pembangunan pertanian antara lain disebabkan oleh perbedaan persepsi antara daerah dan pusat serta antara eksekutif dan legislatif lokal tentang peranan pertanian, rendahnya prioritas dan alokasi anggaran untuk pembangunan pertanian, terbatasnya ketersediaan informasi pertanian, penurunan kapasitas dan kemampuan manajerial penyuluh serta penyuluh pertanian kurang aktif mengunjungi petani (Mayrowani, 2012). Petani dalam pelaksanaannya, memegang peranan penting dalam pencapaian keberhasilan pembangunan pertanian. Penyuluh pertanian sangat penting untuk mendorong dan menggerakkan petani dalam melakukan usahataninya agar lebih efisien dan efektif serta membangun dan menghasilkan sumber daya manusia (SDM) yang berkualitas.

Sumberdaya manusia merupakan faktor esensial dalam organisasi. Sumber daya manusia berfungsi sebagai motor penggerak organisasi dengan segala potensinya. Seiring dengan makin berkembangnya pembangunan 
yang ada, baik dari segi ekonomi, sosial, budaya dan sebagainya, maka makin banyak individu yang terlibat di dalamnya. Individuindividu ini yang bergerak secara aktif dalam mewujudkan pembangunan. Terkait dengan hal tersebut, maka kinerja individu mulai dipandang sebagai hal penting. Kinerja memiliki hubungan dengan pengekspresian potensi pada suatu bidang pekerjaan yang dimiliki individu dalam suatu organisasi. Penyuluh sebagai sumber daya dalam suatu organisasi penyuluhan memiliki potensi yang berfungsi untuk mencapai tujuan organisasi. Kinerja dari penyuluh sendiri merupakan merupakan salah satu cerminan potensi dari sumber daya manusia.

Evaluasi kinerja penyuluhan adalah bagian integral dalam membina profesionalisme penyuluh secara berkelanjutan. Kegiatan evaluasi kinerja penyuluh dilaksanakan secara sistematis dan berkesinambungan untuk mengukur tingkat keberhasilan berdasarkan parameter kinerja penyuluh pertanian dalam melaksanakan tugas dan tangggungjawabnya. Evaluasi kinerja juga dapat dilakukan sesuai pronsip obyektivitas, terukur, akuntabel, partisipatif dan transparan. Hasil dari evaluasi kinerja penyuluh diharapkan dapat menampilkan masalah dan potensi yang ada sebagai bahan analisa untuk perbaikan kinerja penyuluh pertanian kedepan.

Pentingnya peran penyuluhan pertanian menjadikan penyuluhan mendapatkan perhatian yang lebih. Jumlah penyuluh pertanian di Kabupaten Gresik berjumlah 65 orang (Dinas Pertanian Kabupaten Gresik, 2017) dengan jumlah desa sebanyak 330 desa dan 26 kelurahan se Kabupaten Gresik (BPS Kabupaten Gresik, 2017). Ibrahim (2001) menyatakan jika rasio penyuluh terhadap petani kecil tentu memperbesar tugas penyuluh. Rahmawati et al. (2019) juga menyatakan bahwa banyaknya desa yang menjadi wilayah binaan penyuluh akan sulit bagi penyuluh untuk mengimplementasikan program intensifikasi pertanian yang sangat berhubungan dengan informasi teknologi pertanian. Oleh karenanya diperlukan kajian ini untuk mengkaji bagaimana kinerja penyuluh pertanian di Kecamatan Balongpanggang Kabupaten Gresik.

\section{Metodologi}

Waktu dan Lokasi Penelitian

Waktu penelitian dilakukan selama 2 bulan, yaitu pada bulan November hingga Desember 2019. Lokasi penelitian dilakukan di Kecamatan Balongpanggang. Penentuan lokasi dilakukan secara sengaja (purposive) dengan pertimbangan bahwa, berdasarkan data yang diperoleh dari UPT wilayah II yang merupakan UPT di Kabupaten Gresik bagian tengah dengan potensi wilayah pertanian, Kecamatan Balongpanggang merupakan kecamatan dengan luas panen padi terluas serta jumlah produksi tertinggi di bandingkan kecamatan lainnya di wilayah Gresik bagian tengah.

\section{Metode Penentuan Sampel}

Responden yaang diambil sebanyak 7 orang penyuluh BPP Balongpanggang. Metode penentuan sampel menggunakan teknik sensus.

\section{Teknik Pengumpulan Data}

Pengolahan data yang digunakan dalam penelitian ini adalah dengan observasi langsung, wawancara terstruktur (kuesioner) dan pencatatan.

\section{Metode Skoring (Skor)}

Pengolahan data untuk mengetahui kinerja penyuluh dengan menggunakan perhitungan skoring. Cara yang digunakan dalam menyusun data tersebut menggunakan skala likert melalui tabulasi dimana skor responden dijumlahkan. Hasil perhitungan skoring dapat digunakan untuk membuat klasifikasi tingkat kinerja penyuluh. 


\section{Metode Analisis Data}

Analisis data yang digunakan untuk mengetahui tingkat kinerja penyuluh adalah dengan menggunakan analisis Nilai Prestasi Kerja (NPK) berdasarkan Peraturan Menteri Pertanian Nomor 91/Permentan/OT.140/9/2013 tentang

Pedoman Evaluasi Kinerja Penyuluh Pertanian. Perhitungan Nilai Prestasi Kerja (NPK) menggunakan rumus :

NPK $=\frac{\text { Total NEM }}{80} \times 100$

Dimana:

NPK = Nilai Prestasi Kerja Jumlah pengukuran/parameter sebanyak 14, setiap indikator dinilai dengan menggunakan skala 1 sampai dengan 5. Skala 1 menunjukkan kinerja paling rendah dan skala 5 menunjukkan kinerja paling tinggi. Tabel 1. Standar Nilai Prestasi Kerja Penyuluh

\begin{tabular}{lll}
\hline No & Nilai & Prestasi Kerja \\
\hline 1 & 91 ke atas & Sangat baik \\
2 & $76-90$ & Baik \\
3 & $61-75$ & Cukup \\
4 & $51-60$ & Kurang \\
5 & 50 ke bawah & Buruk \\
\hline
\end{tabular}

Sumber: Peraturan Menteri Pertanian Nomor 91/Permentan/OT.140/9/2013 tentang Pedoman Evaluasi Kinerja Penyuluh Pertanian

\section{Hasil dan Pembahasan}

Sumberdaya manusia merupakan faktor esensial dalam organisasi. Sumber daya manusia berfungsi sebagai motor penggerak organisasi dengan segala potensinya. Seiring dengan makin berkembangnya pembangunan yang ada, baik dari segi ekonomi, sosial, budaya dan sebagainya, maka makin banyak individu yang terlibat di dalamnya. Individuindividu ini yang bergerak secara aktif dalam mewujudkan pembangunan. Terkait dengan hal tersebut, maka kinerja individu mulai dipandang sebagai hal penting. Kinerja memiliki hubungan dengan pengekspresian potensi pada suatu bidang pekerjaan yang dimiliki individu dalam suatu organisasi. Penyuluh sebagai sumber daya dalam suatu
Jumlah nilai seluruh pengukuran/parameter yaitu paling rendah 14 (jumlah pengukuran/parameter $=14 \times 1$ ) dan paling tinggi 70 (jumlah pengukuran/parameter $=14 \times 5$ ). Jumlah nilai pengukuran/parameter yang diperoleh penyuluh pertanian disebut Nilai Evaluasi Mandiri (NEM) merupakan ukuran prestasi kerja. Standar NPK Penyuluh Pertanian dinyatakan dalam angka dan sebutan sebagai berikut: organisasi penyuluhan memiliki potensi yang berfungsi untuk mencapai tujuan organisasi. Kinerja dari penyuluh sendiri merupakan merupakan salah satu cerminan potensi dari sumber daya manusia.

Menurut Bahua (2016) kinerja penyuluh pertanian merupakan salah satu bentuk kualitas sumberdaya manusia di bidang pertanian yang dapat membantu petani dalam meningkatkan produksi usaha tani berdasarkan tingkat pengetahuan, ketrampilan dan sikap petani. Kinerja penyuluh pertanian terkait erat dengan peran penyuluh pertanian dalam mengimplementasikan program-program penyuluhan yang dapat merubah perilaku petani kearah yang lebih baik. Terdapat tiga 
peran utama penyuluh yang berhubungan dengan kegiatan-kegiatan penyuluhan yaitu :

1. Peleburan diri atau bersatu dengan masyarakat sasaran.

2. Menggerakkan masyarakat sasaran untuk melakukan perubahan berencana.

3. Memantapkan hubungan sosial dengan masyarakat sasaran.

Kinerja penyuluh pertanian merupakan hasil kerja yang dicapai sesuai tugas dan tanggung jawab yang dilaksanakan secara efektif dan efisien berdasarkan kemampuan, pengalaman serta penggunaan waktu (Herbenu, 2007). Sasaran evaluasi kinerja penyuluh pertanian yaitu penyuluh pertanian PNS dan Tenaga Harian Lepas Tanaga Bantu (THL-TB) penyuluh pertanian yang bertugas di desa/kelurahan, kecamatan, kabupaten/kota provinsi dan pusat. Evaluasi kinerja dilakukan terhadap:

1. Persiapan penyuluhan Pertanian, yang meliputi: a) Membuat data potensi wilayah dan agro ekosistem, b) Memandu (pengawalan dan pendampingan) penyusunan RDKK, c) Penyusunan programa penyuluhan pertanian desa dan kecamatan, d) Membuat Rencana Kerja Tahunan Penyuluh Pertanian (RKTPP);
2. Pelaksanaan Penyuluhan Pertanian, yang terdiri atas: a) Melaksanakan desiminasi/penyebaran materi penyuluhan sesuai kebutuhan petani, b) Melaksanakan penerapan metoda penyuluhan pertanian di wilayah binaan, c) Melakukan peningkatan kapasitas petani terhadap akses informasi pasar, teknologi, sarana prasarana dan pembiyaan, d) Menumbuh dan mengembangkan kelembagaan petani dari aspek kuantitas dan kualitas, e) Menumbuhkan dan mengembangkan kelembagaan ekonomi petani dari aspek kuantitas dan kualitas, f) Meningkatnya produktivitas (dibanding produktivitas sebelumnya, berlaku untuk semua sektor);

3. Evaluasi dan Pelaporan Penyuluh Pertanian, terdiri atas: a) Melakukan evaluasi pelaksanaan penyuluhan pertanian, b) Membuat laporan pelaksanaan penyuluhan pertanian.

Penelitian terhadap evaluasi kinerja penyuluh pertanian di BPP Balongpanggang dilakukan untuk kinerja pada tahun 2019. Data diambil dan diolah berdasarkan pada pedoman evaluasi kinerja Peraturan Menteri Pertanian Nomor 91/Permentan/OT.140/9/2013 kemudian direkapitulasi, sehingga diperolah hasil sebagai berikut:

Tabel 2. Skor Parameter Persiapan Penyuluhan di BPP Balongpanggang

\begin{tabular}{|lll|}
\hline No. & Parameter & Skor rata-rata \\
\hline 1 & Membuat data potensi wilayah dan agro ekosistem & 5 \\
2 & $\begin{array}{l}\text { Memandu (pengawalan dan pendampingan) penyusunan } \\
\text { RDKK }\end{array}$ & 5 \\
3 & $\begin{array}{l}\text { Penyusunan programa penyuluhan pertanian desa dan } 5 \\
\text { kecamatan } \\
4\end{array}$ & $\begin{array}{l}\text { Membuat Rencana Kerja Tahunan Penyuluhan Pertanian } \\
\text { (RKTPP) }\end{array}$ \\
\hline
\end{tabular}

Sumber: Analisis Data Primer (2019)

Berdasarkan tabel 2. penyuluh BPP Balongpanggang mendapatkan nilai tinggi pada semua parameter persiapan penyuluhan. Artinya semua penyuluh telah membuat data wilayah dan agroekosistem, memandu penyusunan RDKK, terlibat dalam penyusunan programa desa dan kecamatan serta penyuluh juga membuat RKTPP. Sesuai dengan Suhanda et al. (2008), perencanaan yang termasuk dalam persiapan penyuluhan 
menempati skor tinggi dalam penilaian kinerja penyuluh. Penyuluh menyadari bahwa untuk menyelenggarakan penyuluhan dengan lancar dibutuhkan persiapan yang baik. Persiapan penyuluhan yang baik dan matang akan Tabel 3. Skor Parameter Pelaksanaan Penyuluhan di BPP Balongpanggang

\begin{tabular}{|c|c|c|}
\hline No & Parameter & Skor rata-rata \\
\hline 1 & $\begin{array}{l}\text { Melaksanakan diseminasi/penyebaran materi penyuluhan } \\
\text { sesuai kebutuhan petani (dalam satu tahun) }\end{array}$ & 3,14 \\
\hline 2 & $\begin{array}{l}\text { Melaksanakan metode penyuluhan dalam bentuk } \\
\text { kunjungan (dalam satu tahun terakhir) }\end{array}$ & 4 \\
\hline 3 & $\begin{array}{l}\text { Melaksanakan metode penyuluhan dalam bentuk } \\
\text { demontrasi/Sekolah lapang (dalam satu tahun terakhir) }\end{array}$ & 1 \\
\hline 4 & $\begin{array}{l}\text { Melaksanakan metode penyuluhan dalam bentuk temu- } \\
\text { temu (dalam satu tahun terakhir) }\end{array}$ & 1 \\
\hline 5 & $\begin{array}{l}\text { Melaksanakan metode penyuluhan dalam bentuk kursus } \\
\text { tani (dalam satu tahun terakhir) }\end{array}$ & 1 \\
\hline 6 & $\begin{array}{l}\text { Melakukan peningkatan kapasitas petani terhadap akses } \\
\text { informasi dalam mengembangkan usahatani }\end{array}$ & 5 \\
\hline 7 & $\begin{array}{l}\text { Menumbuhkan poktan/gapoktan dari aspek kualitas dan } \\
\text { kuantitas }\end{array}$ & 3,14 \\
\hline 8 & $\begin{array}{l}\text { Meningkatkan kelas poktan dari aspek kualitas dan } \\
\text { kuantitas }\end{array}$ & 1,57 \\
\hline 9 & $\begin{array}{l}\text { Menumbuhkan dan mengembangkan kelembagaan } \\
\text { ekonomi petani }\end{array}$ & 1 \\
\hline 10 & $\begin{array}{l}\text { Meningkatkan produksi komoditi unggulan di WKPP } \\
\text { dibandingkan produksi sebelumnya }\end{array}$ & 5 \\
\hline
\end{tabular}

Sumber: Analisis Data Primer (2019)

Pelaksanaan penyuluhan erat kaitannya dengan aktivitas penyuluhan pertanian yang diselenggarakan penyuluh. Parameter dengan nilai tertinggi adalah meningkatkan kapasitas petani terhadap akses informasi dalam mengembangkan usahatani dan Meningkatkan produksi komoditi unggulan di WKPP dibandingkan produksi sebelumnya. Kedua parameter tersebut memperoleh poin 5. Hal ini mengindikasikan bahwa penyuluh BPP Balongpanggang memberikan informasi dan menunjukkan sumber informasi, membangun jejaring kerja antar petani, membangun kemitraan dengan perusahaan east west untuk komoditi kangkung biji serta membantu pembuatan proposal kegiatan misalnya proposal bantuan sarana produksi ke Dinas mencerminkan kebutuhan klien di lapangan, dan akan sangat berguna saat pelaksanaan penyuluhan nanti (Herawati dan Pulungan, 2006). 
sesuai kebutuhan petani dan parameter menumbuhkan kelompoktani (poktan) atau gabungan kelompoktani (gapoktan) dari aspek kualitas dan kuantitas mendapatkan point sebesar 3.14. hal tersebut menunjukkan bahwa penyuluh mampu menyebarkan 5 sampai dengan 7 judul/topik. Topik yang disebarkan kepada petani juga telah disesuaikan dengan kebutuhan petani seperti topik tentang pra tanam padi, penggendalian hama tikus, panen dan pasca panen, pertanian organik, penerapan jajar legowo dan lain-lain. Pertumbuhan poktan/gapoktan baik dari segi kualitas maupun kuantitas juga menjadi perhatian penyuluh dalam melaksanakan penyuluhan. Peningkatan kelas poktan dari aspek kualitas dan kuantitas berdasarkan evaluasi yang telah dilakukan penyuluh menunjukkan adanya Tabel 4. Skor Parameter Evaluasi Penyuluhan di BPP Balongpanggang

\begin{tabular}{|lll|}
\hline No. & Parameter & Skor rata-rata \\
\hline 1 & Melakukan evaluasi pelaksanaan penyuluhan & 3 \\
2 & Membuat laporan pelaksanaan penyuluhan pertanian & 3 \\
\hline
\end{tabular}

Sumber: Analisis Data Primer (2019)

Evaluasi penyuluhan berdasarkan tabel 4 diketahui bahwa parameter melakukan evaluasi pelaksanaan penyuluhan mendapatkan skor rata-rata 3. Artinya pelaksanaan evaluasi dilakukan sebayak 3 kali. Parameter membuat laporan pelaksanaan penyuluhan pertanian juga memperoleh skor 3 .

Artinya penyuluh BPP membuat laporan setiap bulan, triwulan dan tahunan.

Untuk mengetahui kinerja penyuluh BPP Balongpanggang berdasarkan indikator persiapan, pelaksanaan, dan evaluasi diperoleh nilai prestasi kerja pada tabel berikut:

Tabel 5. Hasil Evaluasi Kinerja Penyuluh BPP Balongpanggang

\begin{tabular}{llllll}
\hline No & Nama Penyuluh & $\begin{array}{l}\text { Status } \\
\text { Penyuluh }\end{array}$ & Total NEM & NPK & $\begin{array}{l}\text { Prestasi } \\
\text { Kerja }\end{array}$ \\
\hline 1 & Mashudi & PNS & 54 & 67,5 & $\begin{array}{l}\text { Cukup } \\
\text { Cukup }\end{array}$ \\
2 & Sukono & $\begin{array}{l}\text { THL-TB } \\
\text { PP }\end{array}$ & 52 & 65 & Cukup \\
3 & Suwiji & $\begin{array}{l}\text { THL-TB } \\
\text { PP }\end{array}$ & 51 & 63,75 & Cukup \\
4 & Sukoco & $\begin{array}{l}\text { THL-TB } \\
\text { PP }\end{array}$ & 50 & 62,50 & Cukup \\
5 & Feri Agung P. & $\begin{array}{l}\text { THL-TB } \\
\text { PP }\end{array}$ & 53 & 66,25 & \\
& & THL-TB & 52 & 65 & Cukup \\
6 & Tri Lukito W. & PP & & 63,75 & Cukup \\
\hline
\end{tabular}


PP

Sumber: Analisis Data Primer (2019)

Hasil rata-rata nilai prestasi kinerja penyuluh BPP Balongpanggang adalah sebesar 64,82 dan termasuk pada kategori cukup. Kategori cukup tersebut dikarenakan tidak adanya program penunjang yang sesuai dengan indikator evaluasi. Hal ini tidak sesuai dengan hasil penelitian Hernanda (2015) bahwa sebagian prestasi kerja penyuluh di Kabupaten OKU Selatan berada pada kriteria baik. Seseorang dikatakan memiliki kinerja yang bagus bila berkaitan dan memenuhi standar tertentu (Hickerson dan Middleton, 1975). Indikator yang mendapatkan nilai rendah (nilai 1 poin) yaitu pada tahap pelaksanaan dengan parameter melaksanakan penerapan metode penyuluhan di wilayah binaan dalam bentuk demontrasi/SL, temutemu (temu lapang, temu wicara, temu teknis, temu karya, temu usaha) dan metode dalam bentuk kursus (dalam satu tahun terakhir), serta parameter menumbuhkan dan mengembangkan kelembagaan ekonomi petani dari aspek jumlah dan kualitas. Hal tersebut menunjukkan bahwa terbatasnya dukungan dari pemerintah daerah untuk mendukung kegiatan penyuluhan serta kurang tersedianya fasilitas prasarana dan sarana penyuluhan.

Pelaksanaan penyuluhan dalam bentuk demontrasi di BPP Balongpanggang hanya dilakukan sekali dalam setahun yaitu hanya pada saat pra-tanam, selain itu kelembagaan ekonomi petani yang ada masih belum berbaan hukum. Hal ini sesuai dengan hasil penelitian yang dilakukan oleh Puspandoyo (2018) yang menyatakan bahwa penyebab kurang optimalnya kinerja penyuluh pertanian di Kabupaten Purworejo disebabkan oleh salah satunya yaitu faktor sistem seperti kurangnya dukungan pemerintah daerah untuk mendukung operasional penyuluhan yang mengakibatkan kurangnya sarana prasarana kegiatan penyuluhan dan kurangnya sarana pembelajaran kegiatan penyuluhan bagi penyuluh di setiap balai penyuluhan pertanian tingkat kecamatan seperti lahan demplot, laboratorium pertanian dan lain-lain. Vintarno et al. (2019) menambahkan bahwa keberadaan penyuluhan yang langsung bersentuhan dengan petani, tentunya membutuhkan sarana dan prasaran yang memadai. Pada prakteknya, masih banyak penyuluh yang belum mendapatkan sarana dan prasarana tersebut. Kondisi ini akan berpengaruh pada kinerja penyuluh dalam menjalankan aktivitasnya.

\section{Kesimpulan}

Secara umum, kinerja penyuluh pertanian BPP Balongpanggang berada pada kategori cukup. Belum optimalnya kinerja penyuluh tersebut dikarenakan rendahnya pelaksanaan penyuluhan dalam bentuk demontrasi, temu-temu dan metode dalam bentuk kursus serta rendahnya penumbuhan dan pengembangan kelembagaan ekonomi petani dalam aspek jumlah dan kualitas. Kurangnya fasilitas pendukung kegiatan penyuluhan mengakibatkan rendahnya kinerja penyuluh BPP Balongpanggang, oleh karena itu sebaiknya pemerintah daerah memberikan dukungan terhadap kegiatan penyuluhan dengan mencukupi fasilitas prasarana dan sarana penyuluhan serta meningkatkan anggaran untuk bisa lebih sering melakukan kegiatan seperti demontrasi maupun temutemu, sehingga prestasi kerja penyuluh dapat ditingkatkan.

\section{Daftar Pustaka}

Badan Pusat Statistik Kabupaten Gresik. 2017. Kabupaten Gresik dalam Angka 2017 [online]. Tersedia www://gresikkab.bps.go.id. Diakses 8 April 2019.

Bahua, M.I. 2016. Kinerja Penyuluh Pertanian. Deepublish: Yogyakarta

Herawati, I., dan Pulungan. 2006. FaktorFaktor yang Berhubungan dengan 
Partisipasi Kontak Tani dalam

PerencanaanProgram Penyuluhan

Pertanian (Kasus WUKPP Nyalindung,

Kabupaten Sukabumi). Jurnal

Penyuluhan. 2(2): 107-114.

Herbenu, P.C. 2007. Pengembangan Sumberdaya Petugas Penyuluh Lapangan PPL Pertanian Guna Menghadapi Persaingan dan Meraih Peluang Kerja. Jurnal Ilmu-Ilmu Pertanian. 3(1):1-11.

Hernanda., Tiara, A.P., Fatchiya, A., dan Sarma, M. 2015. Tingkat Kinerja Penyuluh Pertanian di Kabupaten Ogan Komering Ulu (OKU) Selatan. Jurnal Penyuluhan. 11(1): 79-90.

Hickerson, J.F., dan Middleton, J. 1975. Helping People Learn: A Module for Training Trainer. East West-Center: Hawai.

Ibrahim, J.T. 2001. Kajian Reorientasi Penyuluhan Pertanian ke Arah Pemenuhan Kebutuhan Petani di Propinsi Jawa Timur [Disertasi]. Institut Pertanian Bogor: Bogor.

Mayrowani, H. 2012. Pembangunan Pertanian pada Era Otonomi Daerah: Kebijakan dan Implementasi. FORUM PENELITIAN AGRO EKONOMI, Vol. 30, No. 1.

Peraturan Menteri Pertanian Nomor 91 Tahun 2013

Puspandoyo, E. 2018. Evaluasi Kinerja Penyuluh Pertanian di Kabupaten Purworejo Tahun 2018 [Tesis]. STIE Widya Wiwaha: Yogyakarta.

Rahmawati, Baruwadi, M., dan Bahua, M.I. 2019. Peran Kinerja Penyuluh dan Efektivitas Pelaksanaan Penyuluhan pada Program Intensifikasi Jagung. Jurnal Sosial Ekonomi Pertanian, Vol. 15, No. 1.

Suhanda, N.S., Jahi, A., Sugihen, B.G., dan Susanto, D. 2008. Kinerja Penyuluh
Pertanian di Jawa Barat. Jurnal Penyuluhan. 4(2): 100-108.

Surat Perintah Dinas Pertanian Kabupaten Gresik No: 800/178/437.54/2017, 1 Agustus 2017. Gresik. Kepala Dinas Pertanian Kabupaten Gresik.

Vintarno, J., Sugandi, Y.S., dan Adiwisastra, J. 2019. Perkembangan Penyuluhan Pertanian dalam Mendukung Pertumbuhan Pertanian di Indonesia. Jurnal Responsive. 1(3): 90-96. 